\title{
Sriuntifit Sertiun
}

\author{
Papers Presented at the Sixty-First Annual Convention
}

\section{THE PHARMACOGNOSY MUSEUM.}

E. N. GATHERCOAL, CHICAGO.

A museum, according to Webster, is a collection of natural, scientific or literary curiosities. The object of a museum, according to the above definition, would be to arouse and satisfy curiosity, and such is the prime object of all museums. However, the term museum has taken on a broader meaning so as to include among its functions the opportunity for instruction and research, the preservation of historical material and of such articles as are rare in nature and commerce.

Pharmacognosy in a broad sense is the scientific treating of the physical characteristics of medicinal substances, therefore a pharmacognosy museum may be defined as a collection of such natural, scientific and literary articles as are medicinal substances or relate to the same, said collection being designed to arouse and satisfy curiosity, to instruct and give opportunity for research, to preserve rare and historical material. In the most restricted sense, however, pharmacognosy considers only crude animal and vegetable drugs and under this definition only such drugs are included in the pharmacognosy museum. Within these limits every curator of such a museum places his own definition upon the term.

The object of this paper is to present more or less comprehensive answers to the following questions:

(1) What is the value of a pharmacognosy museum to the college of pharmacy? To the teachers? To the students? To the alumni?

(2) How much money should be spent for this museum by the college? How much time given by the teachers to its upbuilding?

(3) What should be the scope of this museum, i. e., what articles should be contained in it?

(4) Where should the museum be situated, how arranged and catalogued and under what rules or arrangements should it be open to afford the utmost facility for use?

The answer to the first question may be presented in two ways: First, the museum of the average college of pharmacy should be subordinate to the library, to the equipment of the laboratories and to the quality of the teachers. That is, nut of the definite sum that is allotted for expenditure by the college, high grade 
teachers should be provided first, well-equipped laboratories next, a modern pharmaceutical library third, and the museum fourth. Second, the value of the museum to the college is very great. No student should be expected to learn the physical characteristics of a drug, chemical or medicine without having the opportunity of seeing, tasting and smelling the article. No teacher should attempt to present the description of any article of pharmacognosy without being fully familiar with its commercial appearance. The museum is the place to learn the appearance of a drug in a way that it will be remembered. For research work in pharmacognosy the value of the museum is unquestioned. To the average

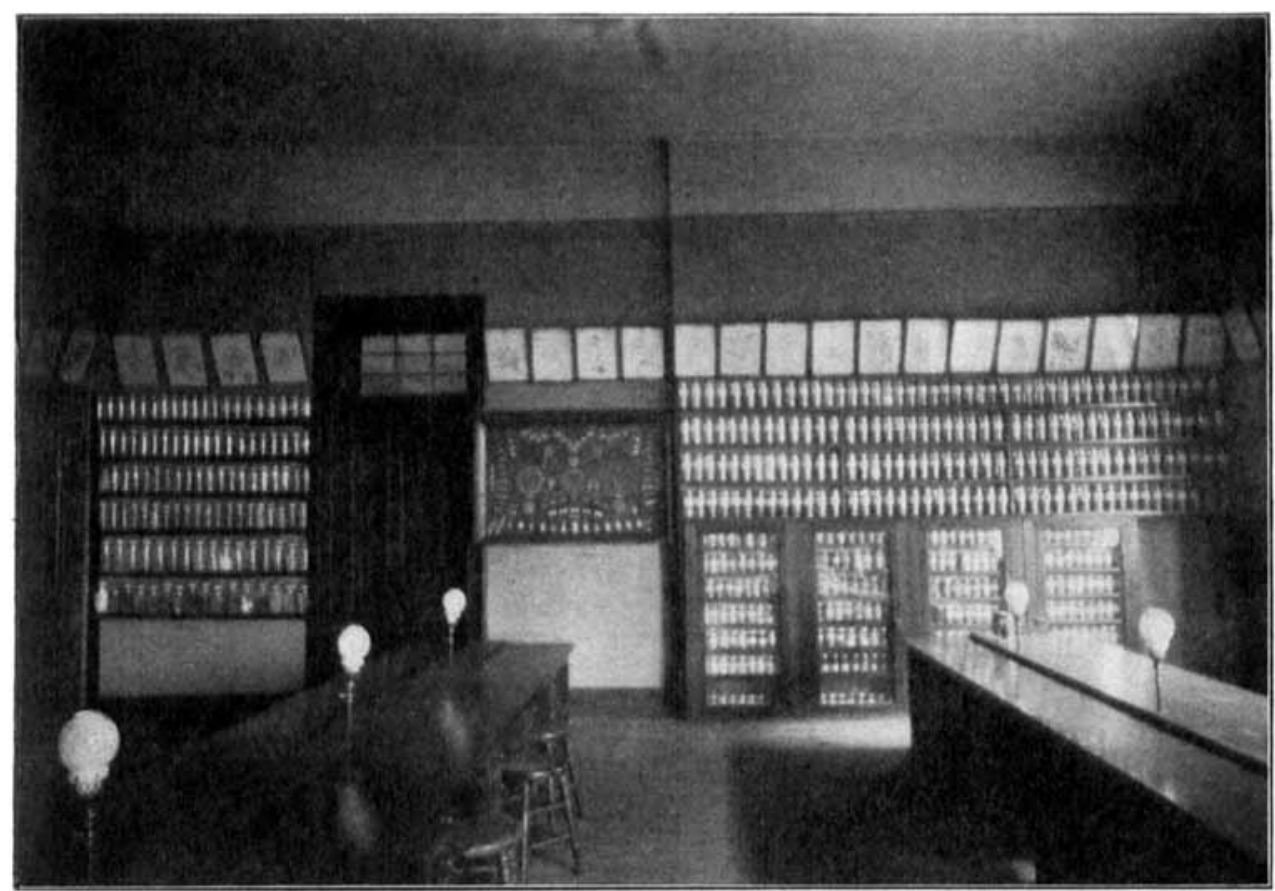

Collection of Rare, Foreign and Powdered Drugs, University of Illinols, School of Pharmacy.

pharmacist, the alumnus, the museum gradually becomes naught but a pleasant memory, largely because it is so situated as to be unavailable for quick and easy use. Where the museums are accessibly located, the alumni often find them of great value for reference. As an advertisement a museum is without doubt an asset to the college. The prospective student in his inspection of the school lingers longest over the orderly array of specimens and cases here presented.

In answer to the next question as to what shall be the scope, the size of the museum, I assume that the ideal of each curator or teacher who chances to read this item: the museum under Dr. Tschirch at the University of Berne with its 50,000 catalogued articles. However, the ideal must give place to the real. Beginning with a college of pharmacy without any collection of drugs that could 
by any courtesy be named a museum: one hundred dollars a year for ten years judiciously expended by a capable, earnest curator would provide a fine nucleus for a good museum. A museum when once established largely grows without any serious expenditure of time or money. Little gifts each of relatively small value to the donor are being constantly received. Specimens of drugs often rare and therefore valuable in the museum are received from time to time for purposes of identification. The residue of samples obtained for inspection from the custom's service may be added to the museum. Samples of fine chemicals and galenicals prepared in the class room find their place in the museum. Col-

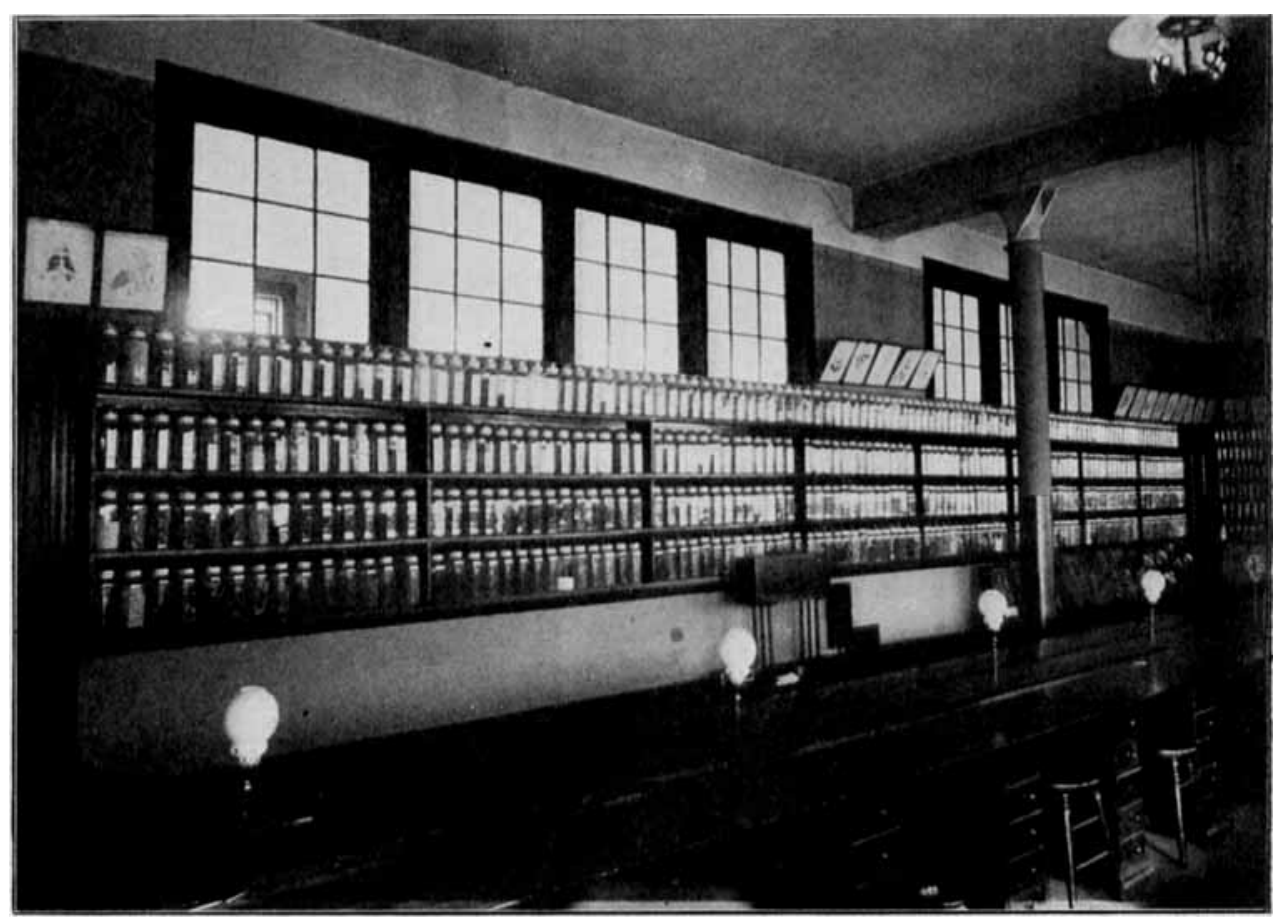

Collection of Official Drugs, University of Illinois, School of Pharmacy.

lections of medicinal chemicals, inorganic and organic, of pharmaceuticals, of alkaloids, active principles and volatile oils are ofttimes presented to the museum by manufacturers of these respective classes of drugs. Crude drugs may be purchased in small quantities, pound or half pounds, from drug importing firms or foreign drug dealers, if the statement is made with the order that the druge are for museum samples. But one of the most important means of supplying the museum with its choicest specimens is through the collection by friends in our own and in foreign countries of items suitable for the museum.

What shall be included in the museum? The pharmacognosy museum may be divided in a general way into the Crude Drug or Pharmacognosy Proper Division, the Chemical Division and the Pharmaceutical Division. 
There will be criticism, I know, against including the chemical and pharmaceutical museums under the general title of Pharmacognosy, however, I defend the title as a good one to apply to the whole College of Pharmacy Museum.

Crude Drug Division.-A crude drug is generally understood to be one consisting of the whole or a part of a plant or animal which has undergone but little change other than drying. Under such a definition the ethereal oils obtained by distillation, the fixed oils obtained by pressure and subsequent purification and the alkaloids and active principles would not be included in the crude drug division,

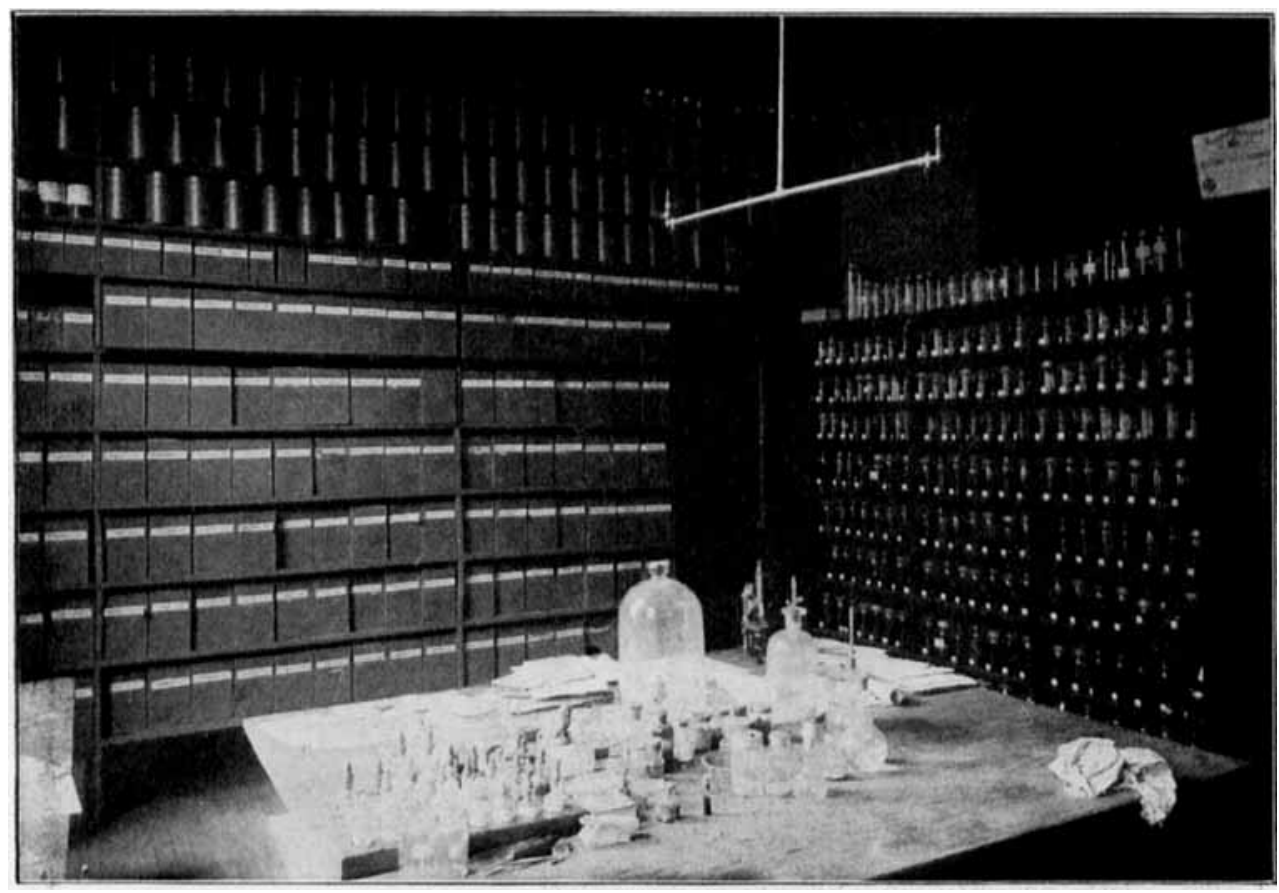

Fresh Drugs in Alcohol and Crude Drugs, University of Illinois, School of Pharmacy.

but the halsams, oleoresins, resins and gums which have exuded naturally or after incision of the plant and even evaporated plant juices should be included.

The number of crude drugs that have been used by man is legion. From the earliest civilization until recent times they have been much more extensively used than chemical substances. Within the last century chemicals as medicines have become more popular.

The crude drugs fall into a number of groups, the most important of which is the Official Crude Drugs. The official group includes all the crude drugs defined in the current U. S. P. and probably should include the drugs of the National Formulary as well. Whether this group should include drugs not official in the United States but that are defined in foreign pharmacopœias is a question, though in the museum in which I am personally interested we have included 
in the Officials not only those drugs defined in the current U. S. P., but also those that have been named in all the revisions of the U. S. P. since the original issue in 1820, and those official in the current pharmacopœias of Europe. Thus our Officials group has become quite large, including upward of 600 titles.

Unofficial Crude Drugs.- The second great group of crude drugs is often designated the Unofficials. This term ordinarily is restricted to those drugs in common use in one's country but not recognized in the national pharmacopœia. However, in our museum we have included in the Unofficials those drugs found in commerce in North America and Europe, but not named in the pharmacopoeias of the United States or Europe.

In the large dispensatories and codexes there is described a long list of unofficial drugs, while an examination of one of the more comprehensive American or European drug price lists reveals the fact that here is named a large number of crude drugs included in neither pharmacopœia nor dispensatory. In fact it seems impossible to find a limit to the Unofficial Group.

Native Drugs of Forcign Countries.-Collections of drugs in common use in countries beyond North America and Europe are of value and interest. Thus the native drugs of China form a very extensive and interesting collection, as do also similar collections from Burma and the East Indies, from India, from several districts of Africa and from South America. Such collections fairly complete are difficult to obtain except from a native or resident of the locality.

Drugs in Original Packages.-The containers in which drugs enter commerce and "original packages" of drugs are always items of interest and instructive value. They may be obtained, usually without cost, from jobbers and importers.

The commercial varieties of a single drug make an interesting collection, such as opium, acacia, cinchona, rhubarb, etc., which enters commerce from different countries or localities, which is of several grades of quality or which occurs in several commercial forms.

Adulterated drugs are often found in commerce, especially in the customs houses and in the store rooms of importers, wholesalers and manufacturers. A sample preserved from each lot of adulterated drug met with will soon form a most valuable collection.

Drug Adulterants.-Substances that are or have been employed for adulterating drugs form an exceedingly interesting portion of the crude drug museum. Specimens of such adulterants may be had by garbling the adulterated drug.

Crude drugs preserved in a fresh state in alcohol or by other means are of especial use for the histological sturdy of drugs. A collection of such fresh material can be gradually accumulated and eventually becomes of great value.

A collection of powdered drugs is a necessity in any well-organized pharmacognosy museum. Powdered drugs have largely replaced whole crude drugs in commerce and the pharmacognocist must be familiar with the gross and microscopic appearance of drugs in powdered form.

An herbarium of drug-yielding plants forms an important portion of the 
pharmacognosy museum. Such an herbarium should be given first place. The drug plants native to the locality of the museum can be increased by purchase, exchange or travel so as to include specimens of the plants yielding all the more important drugs.

There always forms in the museum a collection noteworthy because of the historical interest of the articles included, such as amulets, charms, drugs used in former times but now neglected, drug samples of great age, drugs at one time possessed by a famous pharmacognocist or pharmacist.

Pictures and lantern slides of drugs and of drug-yielding plants, of drug containers, of the process of drug collection and of drug cultivation, etc.; portraits of pharmacognocists of note; manuscripts and books relating to pharmacognosy that because of age or rarity or especial value should be preserved-all of these may be gathered into still another section of the crude drugs division.

Chemical Division.- The chemistry division of the pharmacognosy museum is arranged in a general way similarily to the crude drug division. A chemical may be defined as a substance possessing a definite molecular composition. Thus this division of the museum would contain all those medicinal substances to which have been ascribed chemical formulas.

The articles in the chemical museum naturally fall into a number of groups, which may be designated somewhat as follows:

Inorganic Medicinal Chemicals.

Organic Medicinal Chemicals.

The Elements.

Ores and Chemicals as found in Nature.

Exhibits illustrating the Preparation of Medicinal Chemicals.

Adulterated Chemicals.

Chemical Reagents.

Chemical Apparatus.

The Inorganic and Organic Sections would include, first, those chemicals official in the pharmacopcias of the U. S. and Europe, and, second, those Unofficials mentioned in the dispensatories and price lists. The special collections are of great interest and value, especially where they are fairly complete, nicely arranged and well exhibited.

Pharmaceutical Division.-The pharmaceutical division of the pharmacognosy museum is of especial interest to the pharmacy student and pharmacist because the items contained therein are largely the products of his own skill; articles which he has presented to the museum and of which he possesses an intimate knowledge.

There might be included in the pharmaceutical museum the following sections:

Official Galenicals.

Unofficial Galenicals.

Alkaloids and Active Principles. 
Ethereal and Fixed Oils.

Disinfected Surgical Supplies, including

Cottons, Gauzes, Bandages, Ligatures and Plasters.

Adulterated Pharmaceuticals.

Pharmaceutical Apparatus-

Modern, Ancient, Rare, and Historical.

Pictures, Portraits, Books, Manuscripts, Prescriptions.

Finally, a very short discussion of the fourth point-the location, preservation and arrangement of the museum.

The whole museum may be gathered together and located in one room or it may be located in various rooms throughout the college building. The plan of locating it all at one place, usually a room in connection with the library so that the librarian may also look after the museum, has several advantages, the principal ones of which are: the more impressive appearance made by such an arrangement, the increased facility of use, the advantages presented in cataloging. the assurance of safety which the constant presence of the curator implies.

There are, however, advantages in having the exhibits scattered in the various laboratories and lecture halls, under direct charge of the teachers, especially for the smaller colleges of pharmacy. Thus, much of the formality and inaccessibility of the formal museum is lost: students and teachers, especially, will use the various exhibits much more extensively if they are very conveniently located. Like the dictionary, if it is at your elbow you use it much more often than if it is in the other room. Again the exhibits may often be much better displayed because of the abundance of well lighted wall space in a number of rooms, whereas they would be dark and crowded in a single room. Further, in my opinion, the teachers in each department give more readily of their time and attention to their respective divisions of the museum than if the whole museum was placed in the exclusive charge of one person.

The arrangement of the museum is largely one of personal choice on the part of the curator, though the following points should be observed:

Display each article with such a lighting that it may be studied in detail to the best advantage.

Preserve materials that may deteriorate against deleterious influences, especially sunlight, dust and insects.

Arrange the exhibits in such a way that, given its catalogue number a visitor may easily find any article.

Arrange and label at least the more important exhibits such as the official and unofficial crude drugs, the inorganic and organic chemicals and the official and unofficial galenicals so that any article may be readily found without the catalog numbers.

In the museum of the University of Illinois School of Pharmacy, we have used in the crude drug division for the Officials half-gallon, glass-stoppered, widemouth bottles, each bearing a single-line paper label on the neck of the bottle with 
hand-painted plain square letters about one-half inch high. Each drug is labeled with its pharmacopœial name, the abbreviated name of the pharmacopoia in which it is defined if other than the U. S. P., and the date of the revision in which it was last official.

The Unofficials are in similar bottles with the label bearing, however, only the botanical name of the plant yielding the drug.

Each of these exhibits is arranged alphabetically on open wall shelving in the roomy pharmacognosy laboratory. These exhibits are accessible to any student or visitor during the time the laboratory is open and upon request at any time the college building is open. The samples of many of the U.S. P. drugs are renewed annually.

The rare foreign drug exhibit is contained in screw-cap glass jars with a several line label stating the botanical source of the drug, the country from whence obtained, etc.

The exhibits of adulterated drugs, drug adulterants and commercial varieties are in quart glass-stoppered bottles arranged on open shelving.

The powdered drugs are in half-pint screw cap glass jars in glass front wall cases.

The fresh crude drugs in alcohol or formaldehyde are contained in pint and quart glass-capped jars.

The original packages are mostly exhibited in large glass front wall cases in the pharmacognosy lecture hall.

The herabarium of drug-yielding plants is in a regular herbarium case.

The walls of the laboratory bear many framed prints in color of drug plants.

In the Chemistry Division the inorganic and organic chemicals are displayed in glass-stoppered bottles on shelving in the laboratory, the elements are in a special small case, the apparatus in large glass front wall cases in the chemistry lecture hall.

In the Pharmaceutical Division the galenicals are mostly in pint cork-stoppered bottles, the alkaloids and active principles in slender footed display bottles, and the other displays in various wall cases in the large pharmacy.

In addition to these displays the college possesses portraits in oil of its deceased teachers and of a number of prominent pharmacists of the U. S. and Europē. Hanging from the walls of the lecture halls and library are photographs of every graduate and teacher of the college since the first graduating class fifty-two years ago. In the library are many old and rare books on materia medica, pharmacy and chemistry.

Some day if opportunity offers we may gather this scattered museum into one room, yet we may suffer disappointment if we do so, for the present arrangement is very satisfactory and affords abundant chance for growth.

University of Illinois School of Pharmacy, Chicago. 